\title{
Identifying elders with neuropsychiatric problems in a clinical setting
}

Shilpa Sadanand, Prafulla Shivakumar, N Girish, Santosh Loganathan, Bhavani Shankara Bagepally, Lakshmi Narayanan Kota, Nalini Narayana Reddy, Palanimuthu Thangaraju Sivakumar, Srikala Bharath, Mathew Varghese

Geriatric Clinic and Services, National Institute of Mental Health and Neurosciences, Bangalore, India

\begin{abstract}
Objective: Multiple health problems among the elderly necessitate a comprehensive enquiry to detect problems early and also initiate treatment. We utilized available validated instruments to comprehensively identify older persons with neuro-psychiatric problems including dementia and comorbid medical ailments in the screening desk of the geriatric clinic. Materials and Methods: Individuals aged 6o years and above seeking outpatient care at NIMHANS during a 2-year period (October 2008-September 2010) participated. We used General Health Questionnaire (12-item), AD8, questions to identify psychoses and neurological problems and a checklist of common medical ailments. A probable clinical diagnosis was made at the end by medical personnel based on ICD-10. Results: A total of 5,260 individuals were screened and more than one-third (36.7\%) were women. About 50\% had psychological distress ( $\geq 2$ on GHQ-12), 20.1\% had probable cognitive impairment ( $\geq 2$ on AD8) and about $17 \%$ had symptoms suggestive of psychoses ( $\geq 1$ on Psychoses screener). More than $65 \%$ had either a neurological or neurosurgical problems ( $\geq 1$ on Neurological screener) and headache was the commonest complaint. At probable diagnosis, more than $50 \%$ had a neurological problem and over $30 \%$ had psychiatric disorders. Of these the most common psychiatric illnesses were psychotic disorders (22.0\%), mood disorders (21.4\%) and dementia (14.4\%). The most common medical comorbidity included hypertension (36.4\%), visual impairment (31.8\%) and joint pains $(30.5 \%)$. Nearly $80 \%$ had one or more medical comorbidity in addition to psychiatric illness. The overall set of instruments took about 15-20 minutes. It systematically and comprehensively guided in evaluating the elderly for neuropsychiatric problems and hence was collated to constitute the Instruments for Comprehensive Evaluation of the Elderly (ICE-E). Conclusions: ICE-E was brief, easy to administer and improved decision making even by personnel from a non-medical background. The instrument aided in systematically detecting neuro-psychiatric problems among the elderly (including psychological distress and cognitive changes) and other medical comorbidities.
\end{abstract}

Key words: Comorbidity, elderly, instruments screening, mental health, neuro-psychiatric problems

\section{Introduction}

More than 85 million people are aged above 60 in India and this number is estimated to reach 325 million by the year 2050.$^{[1]}$ Nearly half the health burden in India is expected to be borne by older adults in another 20 years. ${ }^{[2]}$ In India, the neuro-psychiatric component in service delivery is glaringly deficient. Chronic diseases of the brain and mind have not received the desired

\begin{tabular}{|l|l|}
\hline \multicolumn{2}{|c|}{ Access this article online } \\
\hline Quick Response Code: & Website: \\
\hline & www.ruralneuropractice.com \\
\cline { 2 - 3 } & \\
\hline
\end{tabular}

priorities ${ }^{[3]}$ However, the health of the elderly is getting greater attention with the Government of India bringing out the guidelines toward establishing a National Program for Health Care of the Elderly (NPHCE). ${ }^{[4]}$ The guidelines aim at enhancing the health care of the elderly using multiple strategies (geriatric clinic, memory clinics, geriatric wards, domicile visits, etc.) and is being undertaken in phases. Notwithstanding this, neuropsychiatric problems remain relegated to the back. Ignorance, lack of appropriate tools and/or established protocols for managing the neuro-psychiatric problems of the elderly are possible reasons for this disparity in service provision.

While older adults are at high risk of developing multiple comorbid medical conditions, ${ }^{[5]}$ psychiatric morbidity in old age is associated with increased

\section{Address for correspondence:}

Dr. Girish N, Additional Professor of Epidemiology, National Institute of Mental Health and Neurosciences, Bangalore - 560 029, Karnataka, India. E-mail: girishnrao@yahoo.com 
risk of hospitalization ${ }^{[6]}$ and high levels of functional dependency, behavioral problems and cognitive impairment are observed in older adults admitted in general hospitals. ${ }^{[7]}$ Therefore, evaluating older adults for mental health problems and cognitive status is essential. ${ }^{[8]}$ Early detection of these problems confers an advantage to the individual, the health system and the society. However, the challenge is to choose one or more instruments/tools which comprehensively and systematically detects problems and facilitates treatment. This paper attempts to address these issues and discusses our experience in systematically identifying elderly with neuropsychiatric and medical problems.

Theoretically, a combination of validated specific instruments should work well. However, addition of each instrument would increase the time for administration and also make it difficult to administer. The desirable instrument should be concise, easy to administer, serve other purposes such as monitor treatment response and have a reasonably quick scoring time. ${ }^{[9]}$ There are specific screeners for mental health problems such as depression ${ }^{[10,11]}$ or cognitive impairment ${ }^{[12]}$ but none that comprehensively identifies neuropsychiatric problems along with medical ailments. In this study we used existing instruments/tools which could help us comprehensively evaluate adults aged 60 years and above for neuropsychiatric and medical problems at the screening desk in the Geriatric clinic.

\section{Materials and Methods}

Individuals aged 60 years and above registered at the out-patient screening services in National Institute of Mental Health and Neurosciences (NIMHANS) Bangalore, India, were screened by research staff of Geriatric services. Through consultative meetings the frequently and widely used screening instruments, primarily those which systematically detect mental health problems, cognitive impairment, neurological and medical problems among older adults were listed. Those identified in the process [Table 1] were reviewed, based on the brevity (less than 5 minutes to administer), easy to use and feasibility in routine clinical setup. The final set of instruments consisted of four screening instruments, a brief description of which is given below.

The General Health Questionnaire: The General Health Questionnaire ${ }^{[13]}$ is one of the most widely used screening instruments to detect common mental health problems among individuals across ages. The shorter version (GHQ-12) is translated to many local languages ${ }^{[14,15]}$ and is a good clinical screening tool for psychiatric morbidity. ${ }^{[11,16]}$ GHQ-12 has four options for each item, the two less favorable answers are combined and coded 1 and the two more favorable coded as 0 , with total scores ranging from 0 to 12 . With a cut-off score of $\geq 2$ it has good sensitivity and specificity. ${ }^{[15,17]}$

The AD8: The AD8 ${ }^{[18]}$ is a brief 8-item measure to identify cognitive impairment among older adults. The total scores range from 0 to 8 , with a cut-off score of $\geq 2$. It has good sensitivity $(74 \%)$ and specificity $(86 \%)$ for detecting dementia. ${ }^{[18]}$

The Neurological screener: The 12-item questionnaire developed for the Bangalore Urban and Rural Neuroepidemiological (BURN) survey detects symptoms related to major neurological disorders. ${ }^{[19]}$ With a

\section{Table 1: Widely used screening instruments to detect mental health problems and cognitive impairment} among elderly

\begin{tabular}{|c|c|c|}
\hline & Screening instruments & Remarks \\
\hline \multirow[t]{4}{*}{ Mental health problems } & Self-reporting questionnaire SRQ-20/24 & 20-item, self administered \\
\hline & General health questionnaire GHQ-12 & 12-item, self administered, 5 minutes \\
\hline & Geriatric depression scale GDS-15 & 15-item, self administered, 5-10 minutes \\
\hline & Primary health questionnaire & 9-item, self administered, \\
\hline \multirow[t]{9}{*}{ Cognitive impairment } & Mini mental state examination-MMSE & By trained interviewer, 10 minutes \\
\hline & Hindi mental status examination-HMSE & Hindi adaptation of MMSE, For illiterate rural elderly \\
\hline & Clock drawing tests & $\begin{array}{l}\text { For literates, standardized interpretation of drawing by clinician, } \\
2 \text { minutes, }\end{array}$ \\
\hline & Seven minute neurocognitive screening battery & $\begin{array}{l}\text { 4-subtests-memory, verbal fluency, visuo-construction and } \\
\text { orientation, by trained interviewer, 6-11 minutes }\end{array}$ \\
\hline & Mini cog & $\begin{array}{l}\text { For literates; by interviewer, 3-word recall+clock drawing test, } \\
3 \text { minutes }\end{array}$ \\
\hline & AD8 & 8-item, patient administered and/or informant interview, $<3$ minutes \\
\hline & Memory impairment screen & 4-item, by interviewer, 4 minutes \\
\hline & Cognitive impairment test (6-CIT) & 6-item, by interviewer, 3-4 minutes \\
\hline & $\begin{array}{l}\text { General practitioner assessment of } \\
\text { cognition-GPCOG }\end{array}$ & Both patient assessment and informant interview, 6 minutes \\
\hline
\end{tabular}


sensitivity of $95 \%$, specificity of $98 \%$ and a positive predictive value of $68 \%$, the symptom checklist includes headache, speech abnormality, paralysis of limbs, seizures, gait difficulty and memory deficits. The total scores range from 0 to $12 .{ }^{[19]}$

The Psychoses screener: The 4-item screener for detecting psychoses (non-validated) is based on key symptom parameters of psychoses: Delusions, hallucinations, talking/muttering to self and any other strange behaviors. Depending on the presence or absence of the above symptoms, the total scores ranges from 0 to 4 .

Medical Illness Screener: A checklist for common medical ailments, adapted from the Cumulative Illness Rating Scale - Geriatrics, ${ }^{[20]}$ completed the set of instruments along with questions to document the socio-demographic details.

All individuals screened were provisionally diagnosed by medical personnel among the research staff, before being referred to concerned departments for detailed evaluation and treatment as per routine clinical services of the hospital [Figure 1]. Diagnoses such as dementia, mood disorders and other psychiatric illness were made according to ICD-10 criteria. ${ }^{[21]}$ EpiInfo ${ }^{[22]}$ was utilized to develop the database of screened individuals.

\section{Results}

\section{Socio-demographics}

We screened 5,260 individuals aged 60 and above during a 2-year period (October 2008-September 2010). The mean age of respondents was 66.3 years $( \pm 6.24)$, with a majority (71\%) belonging to the 60-69 year age group [Figure 2] and more than one-third were women (36.7\%).

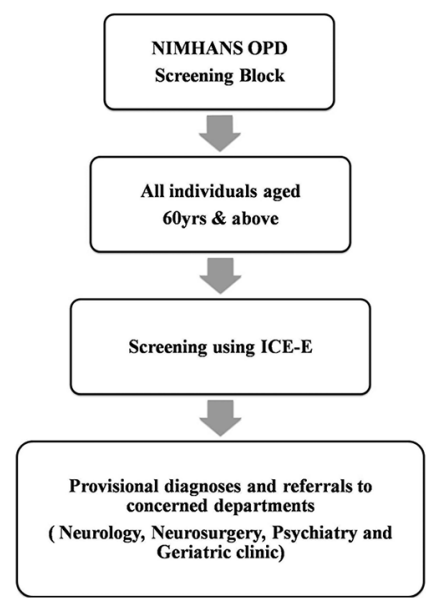

Figure 1: Flow chart depicting screening services for older adults in the hospital

\section{Burden of morbidity}

Mental and neurological problems

GHQ-12 was complete on 4,890 individuals (92.9\%)

[Table 2]. Half of them $(50.0 \%)$ had a score $\geq 2$ indicating possible psychological distress and this was significantly higher among women $(P<0.001)$. The AD8 could be administered to 5,231 individuals (99.4\%) and one-fifth $(20.1 \%)$ had probable cognitive impairment with no significant gender differences. Nearly one-fifth $(16.8 \%)$ had one or more symptoms suggestive of psychoses (talking/muttering/laughing to self: $72.9 \%$; strange behaviors: $69.3 \%$; delusions: $55.8 \%$; hallucinations: $40 \%)$. Nearly two-thirds with psychoses $(61.3 \%)$ were positive for cognitive impairment. Psychotic symptoms were more common among women than men and was statistically significant $(P=0.001)$. More than two-thirds (65.8\%) of those screened had at least one neurological symptom; common ones being headache $(26.3 \%)$, difficulty in walking $(16 \%)$, speech abnormalities (12.6\%) and paralysis of arms or legs $(12.1 \%)$. Significant gender differences were observed: Headache was more common among women, whereas walking difficulty, speech abnormality and

Table 2: Gender differences across ICE-E instruments

\begin{tabular}{lccc}
\hline & Male (\%) & Female (\%) & $\boldsymbol{P}$ value \\
\hline Ghq-12 (score $\geq 2)$ & $1410(45.2)$ & $1032(58.2)$ & $<0.001$ \\
AD8 (score $\geq 2)$ & $632(19.1)$ & $418(21.8)$ & 0.022 \\
$\begin{array}{l}\text { Psychoses screener (score } \geq 1) \\
\begin{array}{l}\text { Presence of both psychotic } \\
\text { symptoms and cognitive }\end{array}\end{array}$ & $481(14.5)$ & $403(20.9)$ & $<0.001$ \\
impairment & $298(8.9)$ & $244(12.6)$ & 0.001 \\
$\begin{array}{l}\text { Neurological screener } \\
\text { (score } \geq 1)\end{array}$ & $2197(66)$ & $1264(65.5)$ & 0.714 \\
$\quad \begin{array}{l}\text { Headache } \\
\text { Walking difficulty }\end{array}$ & $683(20.5)$ & $702(36.4)$ & $<0.001$ \\
$\begin{array}{l}\text { Speech abnormality } \\
\text { Paralysis of arms or legs }\end{array}$ & $547(19.4)$ & $196(10.2)$ & $<0.001$ \\
Neurological screener, Highest frequency of symptoms mentioned &
\end{tabular}

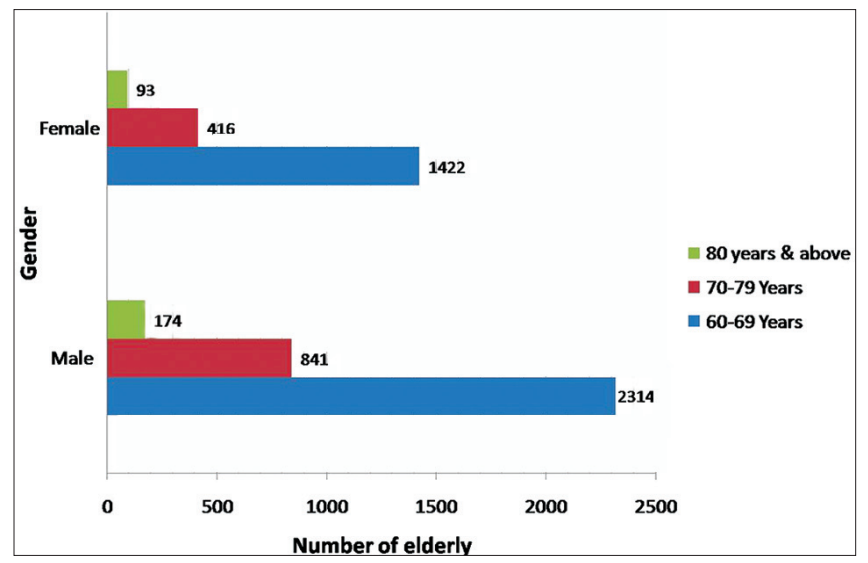

Figure 2: Age distribution among screened population 
paralysis of arms or legs was frequent among men. The provisional clinical diagnosis arrived at is depicted in Figure 3. The data on clinical diagnoses was unavailable for about $8 \%$ of older adults.

Provisional diagnoses among those screened positive Individuals with a provisional diagnosis of mood disorder, other non-psychotic illness such as anxiety, somatoform disorders and with either a neurological or neurosurgical illness were positive $(\geq 2)$ on the GHQ $(87.9 \%, 86.1 \%$ and $40 \%$, respectively) [Table 3]. The psychoses screener identified $95.9 \%$ individuals diagnosed with psychotic illness $(N=365), 50 \%$ of persons with dementia $(N=239)$ and more than $25 \%$ among individuals with substance dependence $(N=97)$. The AD8 identified cognitive impairment among 98.7\% individuals with dementia, $53.9 \%$ with psychotic illness and about $35 \%$ with mood disorders. The neurological screener identified neurological symptoms among $87 \%$ individuals with neurological illness and $69 \%$ with neurosurgical illness.

\section{Medical comorbidity}

Hypertension (36.4\%), visual impairment (31.8\%), musculoskeletal ailments (30.5\%), diabetes mellitus
(21.4\%) and gastro-intestinal disorders (18.2\%) were the common medical illness reported [Table 4]. Diabetes and hypertension were reported by 722 individuals (13.7\%). Musculoskeletal ailments and thyroid disorders were more frequent among women, whereas, stroke and genito-urinary complaints were common in men. Among psychiatrically ill older adults, $77 \%$ had at least one medical comorbidity.

\section{Discussion}

This is a large hospital-based study that enquired into the neuropsychiatric and medical problems among the elderly. The set of individual validated instruments which was put together, assisted the clinician to be systematic and comprehensive. While the focus was on neuropsychiatric problems, medical problems were also included as mental health is integral component of health problems.

Many instruments have been utilized to detect common mental health problems and psychological distress, ${ }^{[10,11,23]}$ but the General health questionnaire ${ }^{[13]}$ is widely used. The shorter version (GHQ-12) works as well as the longer

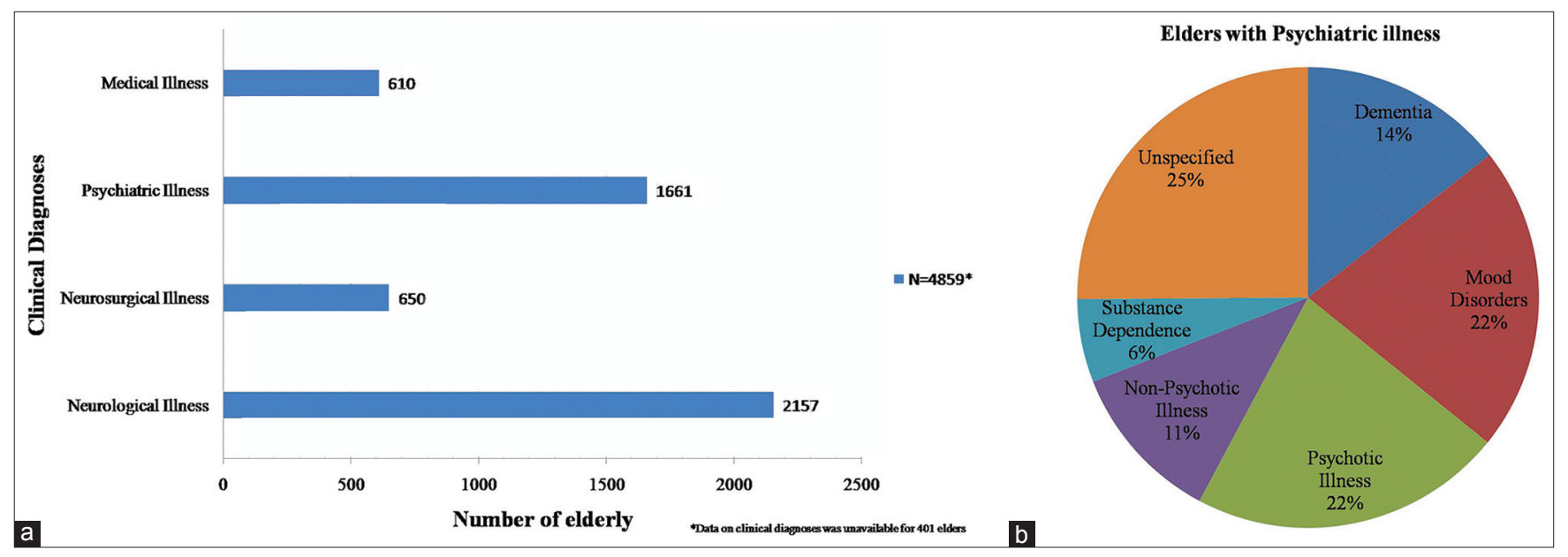

Figure 3: (a and b) Provisional diagnoses among the screened population

Table 3: Comparison of screening instruments and provisional diagnoses

\begin{tabular}{|c|c|c|c|c|c|c|c|c|c|}
\hline & \multirow{2}{*}{$\begin{array}{l}\text { Neurological } \\
\text { illness }\end{array}$} & \multirow{2}{*}{$\begin{array}{l}\text { Neurosurgical } \\
\text { illness }\end{array}$} & \multicolumn{6}{|c|}{ Psychiatric illness } & \multirow{2}{*}{$\begin{array}{c}\text { Medical } \\
\text { illness }\end{array}$} \\
\hline & & & $\begin{array}{c}\text { Mood } \\
\text { disorder }\end{array}$ & $\begin{array}{l}\text { Psychotic } \\
\text { illness }\end{array}$ & $\begin{array}{c}\text { Other } \\
\text { non-psychotic } \\
\text { illness }\end{array}$ & Dementia & $\begin{array}{c}\text { Substance } \\
\text { dependence }\end{array}$ & Unspecified & \\
\hline$N^{\#}$ & 2157 & 650 & 356 & 365 & 187 & 239 & 97 & 417 & 610 \\
\hline Ghq-12* (score $\geq 2)(\%)$ & 42.8 & 40.9 & 87.9 & 76.6 & 86.1 & 48.4 & 45.9 & 68.2 & 34.5 \\
\hline P-4 (score $\geq 1)(\%)$ & 4.8 & 3.7 & 27.2 & 95.9 & 9.1 & 50.2 & 25.7 & 39.5 & 0.8 \\
\hline AD8** (score $\geq 2)(\%)$ & 11.5 & 8.7 & 35.4 & 53.9 & 9.1 & 98.7 & 18.5 & 36.9 & 3.4 \\
\hline $\mathrm{N}-12$ (score $\geq 1)(\%)$ & 87.8 & 68.9 & 51.9 & 38.6 & 47.1 & 69 & 64.9 & 47.2 & 39.8 \\
\hline
\end{tabular}

${ }^{*}$ Ghq-12 could be administered on 4890 individuals, Neurological illness-2045, Neurosurgical illness-610, mood disorders-333, psychotic illness-295,

non-psychotic illness-187, Dementia-159, Substance dependence-87, Unspecified-378, medical illness-602, no diagnosis-388, ${ }^{\star *}$ AD8 could not be administered on 29 individuals $(0.5 \%)$, "Out of 5260 , for 401 individuals, clinical diagnoses data was unavailable 
Table 4: Reported medical comorbidities among those screened

\begin{tabular}{lccc}
\hline & Male & Female & $P$ value \\
& $N=3329(\%)$ & $N=1931(\%)$ & \\
\hline Hypertension & $1187(35.6)$ & $726(37.6)$ & 0.167 \\
Sensory impairment & $1175(35.3)$ & $695(36)$ & \\
$\quad$ Visual impairment & $1044(31.3)$ & $633(32.7)$ & 0.300 \\
$\quad$ Hearing impairment & $233(6.9)$ & $120(6.2)$ & 0.298 \\
Musculoskeletal/Orthopedic & $924(27.7)$ & $682(35.3)$ & $<0.001$ \\
Diabetes & $757(22.7)$ & $368(19)$ & 0.001 \\
Gastro-intestinal & $615(18.4)$ & $342(17.7)$ & 0.530 \\
Stroke & $397(11.9)$ & $135(6.9)$ & $<0.001$ \\
Chronic respiratory diseases & $365(10.9)$ & $171(8.8)$ & 0.016 \\
Genito-urinary & $414(12.4)$ & $108(5.5)$ & $<0.001$ \\
Heart disease & $348(10.4)$ & $156(8.1)$ & 0.005 \\
Seizures & $185(5.5)$ & $78(4)$ & 0.017 \\
Dyslipidemia & $104(3.1)$ & $46(2.4)$ & 0.140 \\
Endocrine-thyroid & $38(1.1)$ & $51(2.6)$ & $<0.001$ \\
Psychiatric illness and medical & & & \\
comorbidities (N=1661) & & & \\
$\quad$ Psychiatric illness and & $262(28)$ & $213(29.4)$ & \\
1-medical comorbidity & & & \\
$\begin{array}{l}\text { Psychiatric illness and } \\
\text { 2-medical comorbidity }\end{array}$ & $194(20.7)$ & $164(22.6)$ & \\
$\begin{array}{l}\text { Psychiatric illness and 3 or } \\
\text { more medical comorbidities }\end{array}$ & $276(29.5)$ & $170(23.5)$ & \\
\hline
\end{tabular}

version (GHQ-28) ${ }^{[13]}$ and is useful in detecting anxiety, depression, social dysfunction and loss of confidence among older adults. ${ }^{[24]}$ The four questions to identify psychotic symptoms complemented the GHQ-12 in identifying both severe and common mental health disorders. Memory deficit seen in dementia is often overlooked as age-related memory loss; hence evaluation of cognitive status among elderly is important. Mini Mental Status Examination (MMSE), Hindi Mental State Examination (HMSE), clock drawing tests, memory impairment screen andAD8 identify cognitive impairment. ${ }^{[12,23,25-27]}$ Of these, MMSE is widely used while AD8 is a new addition that is not frequently used in the Indian setting. However, AD8 is quick, informant based, is sensitive for cognitive change among elderly and reliably differentiates demented from non-demented individuals. ${ }^{[28]}$ Thus, AD8 can be used as a common screening tool to identify cognitive change regardless of the etiology. ${ }^{[18,28]}$ The screener from the BURN survey ${ }^{[19]}$ helped to identify a large proportion of individuals with neurological problems and is simple, comprehensive and brief.

Utilizing the validated screening instruments as a combination has given us unique insights: It aided in picking up a substantial number of psychiatric and neurological cases which would otherwise have gone undetected. GHQ reveals the frequent sleep disturbances amongst older people, ${ }^{[29]}$ and also identify the hidden burden of psychological distress among elders with neurological illness. The psychoses screener besides identifying severe mental health problems complemented the AD8 in identifying psychotic symptoms frequently seen in persons with dementia. ${ }^{[30]}$ In addition, the set of instruments was easy to use and did not pose any major problems in administration. The provisional diagnosis was made by a trained medical doctor. However, a final confirmation by a psychiatrist using standard measures would have been ideal.

\section{Burden of morbidity \\ Psychological distress}

Nearly half of the elderly screened by GHQ scored above the cutoff indicating psychological distress and the gender difference were significant (more women than men). Earlier studies reports greater distress with increasing medical morbidity and that women experience greater distress than men. ${ }^{[31]}$

\section{Mental and neurological problem}

Psychotic symptoms in older persons have various causes: Progressive dementing illness, late-onset schizophrenia, delusional disorders, early onset psychotic illness extending in late life, late onset mood disorders, psychotic disorders caused by medical conditions or medications and delirium. ${ }^{[30,32,33]}$ In the present study, psychotic symptoms were more commonly observed as a result of late-onset psychosis, dementia with psychotic symptoms and also amongst those with late-onset mood disorders. The psychotic symptoms were more commonly observed among older women than men which corresponds to previous literature. ${ }^{[34]}$

Depression is the most common mental health problem among the elderly in India, ${ }^{[35]}$ followed by anxiety disorders, dementia and substance dependence. ${ }^{[36-38]}$ In our study we found preponderance of psychotic illness and mood disorders (including depression), possibly due to use of separate instruments. Headache was the most common symptom among individuals positive on the neurological screener and was reported mostly by older adults with depression, dysthymia or somatoform disorders. Our study supports finding by Drayer and colleagues that older adults with somatic complaints such as headache or fatigue may actually be depressed and rating scales should consider these symptoms for an accurate measure of depression severity. ${ }^{[39]}$

\section{Medical morbidity}

Hypertension, sensory impairment (vision and hearing), musculoskeletal ailments, diabetes and gastro-intestinal complaints in that order, were the common medical 
conditions detected. These are comparable to other Indian studies, ${ }^{[36,40-44]}$ including, the observed significant differences between women and men. ${ }^{[5,40,44]}$ and the proportion of other medical conditions common among the elderly such as stroke, chronic respiratory diseases, genitourinary complaints, heart diseases and seizures. ${ }^{[45,46]}$ Stroke and genitourinary complaints are common among men than women. ${ }^{[46,47]}$ Among elders with psychiatric illness, a majority had one or more co-morbid medical conditions which is comparable to earlier studies. ${ }^{[5,48]}$

\section{Healthcare seeking}

Majority of the individuals screened were aged between 60-69 years and almost two-thirds were men. While there are similar reports, ${ }^{[36,44,49]}$ the gender differences in seeking care (more men than women) is noteworthy. That a greater proportion of male elderly in 60-69 year age group seek care presents a two-fold challenge: The need to develop appropriate services for the visiting group and importantly as there are multiple comorbidities and particularly chronic ones then the greater need for follow-up care.

\section{Conclusions}

This is the first large study which has comprehensively screened and reported neuropsychiatric and medical problems among the elderly who seek health care. Neuropsychiatric problems among geriatric group are highly prevalent. ${ }^{[37]}$ Depression, the most common disorder ${ }^{[48,50]}$ along with memory impairment among elderly patients go undetected as age-related changes and thus are not counted as treatable conditions. The substantial burden of neuro-psychiatric problems is overlooked and presence of psychological distress among persons with neurological and neurosurgical patients are neglected. Our study adopted four commonly used screening instruments to comprehensively evaluate the elderly for a wide array of neuro-psychiatric problems which could be referred to as Instruments for Comprehensive Evaluation of the Elderly (ICE-E). The experience using ICE-E was that it was comprehensive brief, easy to administer, not personnel intensive and could be used by non-medical personnel with adequate training. Apart from aiding the diagnostician, the instrument assists clinician in planning better management strategies.

\section{References}

1. World Health Organization. World Population Ageing 1950-2050. 2002. Available from: http://www.un.org/esa/population/publications/ worldageing 19502050/ [Last accessed on 2011 Jan 21].
2. Chatterji S, Kowal P, Mathers C, Naidoo N, Verdes E, Smith JP, et al. The health of aging populations in China and India. Health Aff 2008;27:1052-63.

3. Sousa RM, Ferri CP, Acosta D, Albanese E, Guerra M, Huang Y, et al. Contribution of chronic diseases to disability in elderly people in countries with low and middle incomes: A 10/66 Dementia Research Group population-based survey. Lancet 2009;374:1821-30.

4. Ministry of Health and Family Welfare, Government of India, Operational Guidelines, National Programme for the Health Care of the Elderly (NPHCE). 2011. Available from: http://mohfw.nic.in/showfile. php?lid=1145 [Last accessed on 2012 Aug 07].

5. Joshi K, Kumar R, Avasthi A. Morbidity profile and its relationship with disability and psychological distress among elderly people in Northern India. Int J Epidemiol 2003;32:978-87.

6. Ng TP, Feng L, Chiam PC, Kua EH. Psychiatric morbidity and acute hospitalization in elderly people. Int Psychogeriatr 2006;18:701-11.

7. Goldberg SE, Whittamore KH, Harwood RH, Bradshaw LE, Gladman JR, Jones RG. The prevalence of mental health problems among older adults admitted as an emergency to a general hospital. Age Ageing 2012;41:80-6.

8. Wray LO, Mavandadi S, Klaus JR, Tew JD Jr, Oslin DW, Sweet RA. The association between mental health and cognitive screening scores in older veterans. Am J Geriatr Psychiatry. 2012;20:215-27.

9. Mulrow CD, Williams JW, Gerety MB, Ramirez G, Montiel OM, Kerber C. Case-finding instruments for depression in primary care settings. Ann Intern Med 1995;122:913-21.

10. Ganguli M, Dube S, Johnston JM, Pandav R, Chandra V, Dodge HH. Depressive symptoms, cognitive impairment and functional impairment in a rural elderly population in India: A Hindi version of the geriatric depression scale (GDS-H). Int J Geriatr Psychiatry 1999;14:807-20.

11. Patel V, Araya R, Chowdhary N, King M, Kirkwood B, Nayak S, et al. Detecting common mental disorders in primary care in India: A comparison of five screening questionnaires. Psychol Med 2008;38:221-8.

12. Ganguli M, Ratcliff G, Chandra V, Sharma S, Gilby J, Pandav R, et al. A Hindi Version of the MMSE: The Development of a cognitive screening instrument for a largely illiterate rural elderly population in india. Int J Geriatr Psychiatry 1995;10:367-77.

13. Goldberg DP, Gater R, Sartorius N, Ustun TB, Piccinelli M, Gureje O, et al. The validity of two versions of the GHQ in the WHO study of mental illness in general health care. Psychol Med 1997;27:191-7.

14. Sriram TG, Chandrashekar CR, Isaac MK, Shanmugham V. The General Health Questionnaire (GHQ) Comparison of the English version and a translated Indian version. Soc Psychiatry Psychiatr Epidemiol 1989;24:317-20.

15. Kuruvilla A, Pothen M, Philip K, Braganza D, Joseph A, Jacob KS. The validation of the Tamil version of the 12 item general health questionnaire. Indian J Psychiatry 1999;41:217-21.

16. Patel V, Pereira J, Mann AH. Somatic and psychological models of common mental disorder in primary care in India. Psychol Med 1998;28:135-43.

17. Jacob KS, Bhugra D, Mann AH. The validation of the 12-item General Health Questionnaire among ethnic Indian women living in the United Kingdom. Psychol Med 1997;27:1215-7.

18. Galvin JE, Roe CM, Powlishta KK, Coats MA, Muich SJ, Grant E, et al. The AD8 A brief informant interview to detect dementia. Neurology 2005;36:559-64.

19. Gourie-Devi M, Gururaj G, Satishchandra P, Subbakrishna DK. Prevalence of neurological disorders in Bangalore, India: A community-based study with a comparison between urban and rural areas. Neuroepidemiology 2004;23:261-8.

20. Miller MD, Paradis CF, Houck PR, Mazumdar S, Stack JA, Rifai AH, et al. Rating chronic medical illness burden in geropsychiatric practice and research: Application of the Cumulative Illness Rating Scale. Psychiatry Res 1992;41:237-48.

21. World Health Organization. The ICD-10 Classification of Mental and Behavioural Disorders. New Delhi, India: AITBS Publishers and Distributors; 2007.

22. Centers for Disease Control and Prevention (CDC). Epi Info[TM] 3.5.1. 2008.

23. Burns A. Rating scales in old age psychiatry. BrJ Psychiatry 2002;180:161-7. 
24. Cheung YB. A confirmatory factor analysis of the 12-item General Health Questionnaire among older people. Int J Geriatr Psychiatry 2002;17:739-44.

25. Lorentz WJ, Scanlan JM, Borson S. Brief screening tests for dementia. Can J Psychiatry 2002;47:723-33.

26. Ganguli M, Hendrie HC. Screening for cognitive impairment and depression in ethnically diverse older populations. Alzheimer Dis Assoc Disord 2005;19:275-8.

27. Ismail Z, Rajji TK, Shulman KI. Brief cognitive screening instruments: An update. Int J Geriatr Psychiatry 2010;25:111-20.

28. Galvin JE, Roe CM, Xiong C, Morris JC. Validity and reliability of the AD8 informant interview in dementia. Neurology 2006;67:1942-8.

29. Mazzotti DR, Guindalini C, Sosa AL, Ferri CP, Tufik S. Prevalence and correlates for sleep complaints in older adults in low and middle income countries: A 10/66 Dementia Research Group study. Sleep Med 2012;13:697-702.

30. Brown FW. Late-life psychosis: Making the diagnosis and controlling symptoms. Geriatrics 1998;53:26-8, 37-8, 41-2.

31. Prakash IJ. Women and ageing. Indian J Med Res 1997;106:396-408.

32. Soares JC, Gershon S. Therapeutic targets in late-life psychoses: Review of concepts and critical issues. Schizophr Res 1997;27:227-39.

33. Lacro JP, Jeste DV. Geriatric psychosis. Psychiatr Q 1997;68:247-60.

34. Hassett A. A descriptive study of first presentation psychosis in old age. Aust N Z J Psychiatry 1999;33:814-24.

35. Shaji KS, Jithu VP, Jyothi KS. Indian research on aging and dementia. Indian J Psychiatry 2010;52(Suppl 1):148-52.

36. Silva Pereira YD, Estibeiro A, Dhume R, Fernandes J. Geriatric patients attending tertiary care psychiatric hospital. Indian J Psychiatry 2002;44:326-31.

37. Sood A, Singh P, Gargi PD. Psychiatric morbidity in non-psychiatric geriatric inpatients. Indian J Psychiatry 2006;48:56-61.

38. Tiwari SC. Geriatric psychiatric morbidity in rural northern India: Implications for the future. Int Psychogeriatr 2000;12:35-48.

39. Drayer RA, Mulsant BH, Lenze EJ, Rollman BL, Dew MA, Kelleher K, et al. Somatic symptoms of depression in elderly patients with medical comorbidities. Int J Geriatr Psychiatry 2005;20:973-82.

40. Prakash O, Gupta LN, Singh VB, Singhal AK, Verma KK. Profile of psychiatric disorders and life events in medically ill elderly: Experiences from geriatric clinic in Northern India. Int $\mathrm{J}$ Geriatr Psychiatry 2007;22:1101-5.

41. Tiple P, Sharma SN, Srivastava AS. Psychiatric morbidity in geriatric people. Dement Geriatr Cogn Disord 2006;48:88-94.

42. Singh GP, Chavan BS, Kaur P, Bhatia S. Physical illnesses among psychiatric outpatients in a tertiary care health institution: A prospective study. Indian J Psychiatry 2006;48:52-5.

43. Shah B, Prabhakar AK. Chronic morbidity profile among elderly. Indian J Med Res 1997;106:265-72.

44. Purty AJ, Bazroy J, Kar M, Vasudevan K, Veliath A, Panda P. Morbidity pattern among the elderly population in the rural area of Tamil Nadu, India. Turk J Med Sci2006;36:45-50.

45. Krishnaswamy B, Sein UT, Munodawafa D, Varghese C, Venkataraman K, Anand L. Ageing in India. Ageing Int 2008;32:258-68.

46. Das SK, Biswas A, Roy J, Bose P, Roy T, Banerjee TK, et al. Prevalence of major neurological disorders among geriatric population in the metropolitan city of Kolkata. J Assoc Physicians India 2008;56:175-81.

47. Dhar HL. Gender, aging, health and society. J Assoc Physicians India 2001;49:1012-20.

48. Chaudhury S, Chakraborty R, Seby K. Prevalence of psychiatric and physical morbidity in an urban geriatric population. Indian J Psychiatry 2011;53:121-7.

49. Singh N, Chopra H, Singh JV, Bhatnagar M, Garg SK, Bajpai SK. The psycho-social profile of the elderly people in urban area of Meerut city. J Indian Acad Geriatr 2009;5:165-70.

50. Varghese M, Patel V. The Graying of India. In: Agarwal SP, Goel DS, Ichhpujani RL, Salhan RN, Shrivastava S, editor. Mental Health: An Indian Perspective 1946-2000. New Delhi, India: Directorate General of Health Services, Ministry of Health and Family Welfare; 2004. p. $240-8$.

How to cite this article: Sadanand $S$, Shivakumar $P$, Girish N, Loganathan S, Bagepally BS, Kota LN, et al. Identifying elders with neuropsychiatric problems in a clinical setting. J Neurosci Rural Pract 2013, 4(Suppl 1):s24-30.

Source of Support: Nil. Conflict of Interest: None declared. 